\title{
Aging is associated with increased activities of matrix metalloproteinase- 2 and -9 in tenocytes
}

\author{
Tung-Yang $\mathrm{Yu}^{1,2+}{ }^{\text {, Jong-Hwei S Pang }}{ }^{2+}{ }^{2}$ Katie Pei-Hsuan $\mathrm{Wu}^{1}$, Max J-L Chen ${ }^{1}$, Chien-Hung Chen ${ }^{1}$ \\ and Wen-Chung Tsai ${ }^{1,3^{*}}$
}

\begin{abstract}
Background: Most tendon pathology is associated with degeneration, which is thought to involve cyclic loading and cumulative age-related changes in tissue architecture. However, the association between aging and degeneration of the extracellular matrix (ECM) in tendons has not been investigated extensively.

Methods: We examined tenocytes from Achilles tendons taken from rats of three different ages $(2,12$, and 24 months). Tenocyte viability was assessed using the 3-[4,5-dimethylthiazol-2-yl]-2,5-diphenyltetrazolium bromide (MTT) assay. Quantitative real-time polymerase chain reaction (PCR) was used to determine the levels of mRNAs that encode type-I collagen, matrix metalloproteinase (MMP)-2 and -9 , tissue inhibitor of metalloproteinase (TIMP)-1 and -2 and transforming growth factor (TGF)- $\beta 1$. Gelatin zymography was used to evaluate the enzymatic activities of MMP-2 and -9. Furthermore, the concentration of TGF- $\beta 1$ in conditioned medium was evaluated using enzyme-linked immunosorbent assay (ELISA).
\end{abstract}

Results: The results of the MTT assay showed that the number of viable tenocytes decreased with age. No differences were observed in the levels of mRNAs that encode type-I collagen and TGF- $\beta 1$ among the three age groups, and the TGF- $\beta 1$ concentration did not change with age. However, mRNAs that encode MMP-2 and -9 were significantly more abundant in tenocytes from the aging group, and gelatin zymography revealed that the enzymatic activities of MMP-2 and -9 also increased significantly with age. Furthermore, as compared with young group, mRNAs that encode TIMP-1 and -2 were significantly decreased in tenocytes from the aging group.

Conclusions: Activities of MMP-2 and MMP-9 in tenocytes increase with age. This might provide a mechanistic explanation of how aging contributes to tendinopathy or tendon rupture with age.

Keywords: Aging, Collagen, Matrix metalloproteinase, Tenocytes, Transforming growth factor-beta 1

\section{Background}

Age is commonly associated with increased prevalence of tendinosis and injury [1-3], and degenerative changes are commonly found in the tendons of people over 35 years of age [4]. The most common pathology observed during surgery for chronic painful Achilles tendon is degeneration or tendinosis [2]. In addition, most pathological changes in spontaneously ruptured tendons are degenerative [4].

Little is known about the roles of mechanisms responsible for aging in the degeneration of tendons, but

\footnotetext{
*Correspondence: tsaiwc@adm.cgmh.org.tw

${ }^{\dagger}$ Equal contributors

'Departement of Physical Medicine and Rehabilitation, Chang Gung Memorial Hospital, Linkou, Taiwan

${ }^{3}$ College of Medicine, Change Gung University, Kwei-Shan Tao-Yuan, Taiwan Full list of author information is available at the end of the article
}

biophysical investigations have implicated a role for imbalanced homeostatic turnover of the extracellular matrix (ECM) of the tendon [5-7]. Accumulated physical damage on the rotator cuff increased cleavage of matrix components in aging tendons [8]. It appears that both insufficient synthesis and increased degradation of ECM might contribute to the mechanical deterioration of tendons.

The degree of ECM breakdown is controlled by the release of matrix metalloproteinases (MMPs) and their inhibition by tissue inhibitor of metalloproteinases (TIMPs) [9]. Several MMPs have been implicated in chronic tendon pathologies, with increased levels of expression of MMP-1, MMP-2, MMP-9, MMP-19, MMP23 and MMP-25, and decreased levels of expression of
C Biomed Central 
MMP-3, MMP-10, MMP-12, MMP-27 and TIMP-2 in either ruptured or painful tendons [5-8,10]. However, there is currently no direct evidence of an association between age and the activities of MMPs. Gelatinases (MMP-2 and -9) cleave soluble type-IV collagen [11], as well as both native and reconstituted type-I collagen [12]. Cyclic strain may increase the levels of both MMP2 and MMP-9 in horse superficial digital flexor tendons and human Achilles tendons [5]. Moreover, aging enhances this mechanically induced MMP activity [13]. Therefore, it is crucial to investigate whether aging affects the enzymatic activities of MMP-2 and -9 and their physiologic inhibitors, TIMP-2 and -1 directly, as this could ultimately improve our understanding of the mechanism that accounts for the increasing incidence of tendinopathy in aging populations.

The transforming growth factor (TGF) $\beta$ gene family consists of at least five homologous genes that encode proteins with a wide range of effects on the differentiation and activity of many cell types [14]. Three homodimeric isoforms (TGF- $\beta 1,-\beta 2$, and $-\beta 3$ ) exist in mammalian cells [15]. Studies reveal that TGF- $\beta 1$ selectively stimulates the synthesis of connective tissue matrix components both in vivo and in vitro, to control the formation and degradation of connective tissues $[16,17]$. These effects might be augmented by reducing the synthesis of proteinases (MMPs) [18-20], or by increasing the expression of tissue inhibitors of MMP (TIMPs) $[20,21]$. A study on the effects of aging on the synthesis of rabbit fibroblast matrix showed that the fibroblasts from aging rabbits produced significantly less collagen in response to TGF- $\beta 1$ than fibroblasts from young rabbits did [22]. However, whether aging alters the secretion of TGF- $\beta$ in tenocytes has not yet been investigated.

The present study was undertaken to assess the effects of aging on the expression of six mRNAs, the enzymatic activities of MMP-2 and -9 , and the secretion of TGF$\beta 1$ from tenocytes.

\section{Methods}

All procedures were approved by the Institutional Animal Care and Use Committee of Chung Gung Memorial Hospital, Taiwan.

\section{Primary culture of rat Achilles tenocytes}

Tenocytes were obtained from Sprague-Dawley rats, as previously described [23]. The animals were divided into 3 groups by age: young ( 2 months), middle-aged (12 months), and near senescence (old, 24 months). Samples from passages 2-4, which contained fibroblasts with normal growth rates and shapes, were used. Similar cell densities were used in each group at the start of the experimental process, and all experiments were performed at least in triplicate.

\section{3-[4,5-Dimethylthiazol-2-yl]-2,5-diphenyltetrazolium bromide (MTT) assay}

Tenocytes from all age groups were cultured, and cell viability was measured by MTT assay both $24 \mathrm{~h}$ and $48 \mathrm{~h}$ after plating. After the addition of MTT $(50 \mu \mathrm{g} / \mathrm{ml})$, the mixture was incubated at $37^{\circ} \mathrm{C}$ for $1 \mathrm{~h}$. Next, the MTT solution was discarded, and $1 \mathrm{ml}$ of dimethyl sulfoxide (DMSO) was added to dissolve the formazan crystals. The optical density of the aliquots was measured at $570 \mathrm{~nm} \mathrm{OD}_{570} \mathrm{~nm}$ using a spectrophotometer $\left(\mathrm{VICTOR}^{\mathrm{TM}} \mathrm{X} 3\right.$ Multilabel Plate Reader; PerkinElmer Inc, Waltham, MA). Fold changes in the OD570 nm values for the middle-aged and senescent tenocytes were calculated relative to the values for young tenocytes.

\section{Isolation of RNA, reverse transcription, and quantitative real-time polymerase chain reaction (PCR)}

Tenocytes were lysed by using a guanidine isothiocyanate buffer. Subsequently, total RNA was extracted with phenol and chloroform/isoamyl alcohol (49:1) to remove proteins and genomic DNA. One microgram of total RNA was reverse-transcribed into complementary DNA (cDNA) by incubating it with 200 units of reverse transcriptase in $20 \mu \mathrm{l}$ of reaction buffer containing $0.25 \mu \mathrm{g}$ of random primers and $0.8 \mathrm{mM}$ dNTPs at $42^{\circ} \mathrm{C}$ for $1 \mathrm{~h}$. Quantitative real-time PCR was performed using an SYBR Green and Mx3000P ${ }^{\mathrm{TM}}$ QPCR system (Stratagene, La Jolla, CA). Aliquots (20 ng) of cDNA were used for each quantitative PCR, and each reaction was run in triplicate. The primers used are shown in Table 1. Relative gene expressions between experimental groups were determined using MxPro software (Stratagene, La Jolla, $\mathrm{CA}$ ), and the mRNA that encodes glyceraldehyde3-phosphate dehydrogenase (GAPDH) was used as an internal control.

\section{Gelatin zymography}

The presence of MMP-2 and MMP-9 in conditioned medium was detected using gelatin zymography, which was performed under non-reducing conditions in a $7.5 \%$ SDS-polyacrylamide gel containing $2 \mathrm{mg} / \mathrm{ml}$ gelatin (Mini-PROTEAN II system; Bio-Rad Laboratories Ltd, Hempstead, UK). Gels were washed in 2.5\% Triton X100 to remove SDS and allow renaturation of MMPs, before they were transferred to a solution containing $50 \mathrm{mM}$ Tris ( $\mathrm{pH} 7.5), 5 \mathrm{mM} \mathrm{CaCl} 2$, and $1 \mathrm{mM} \mathrm{ZnCl}_{2}$, followed by incubation at $37^{\circ} \mathrm{C}$ for $18 \mathrm{~h}$. After staining with Coomassie brilliant blue R250 (Bio-Rad Laboratories, Hercules, CA), pro-MMPs and active MMPs were observed as white lysis bands produced by gelatin degradation. To quantify MMP-2 and MMP-9 activities, densitometric analysis was performed using 1D Digital Analysis Software (Kodak Digital Science; Eastman Kodak Company, Rochester, NY). The values of MMP-2 
Table 1 Primer sequences of target genes for real-time PCR

\begin{tabular}{|c|c|}
\hline Target genes & Primer sequence \\
\hline \multirow[t]{2}{*}{ GAPDH } & 5' AGTCTACTGGCGTCTTCA 3' forward \\
\hline & 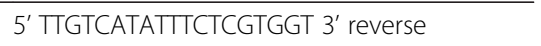 \\
\hline \multirow[t]{2}{*}{ COL1A1 } & 5' TACAGCACGCTTGTGGATG 3' forward \\
\hline & 5' TTGGGATGGAGGGAGTTA 3' reverse \\
\hline \multirow[t]{2}{*}{$\overline{M M P-2}$} & 5' GGAAGCATCAAATCGGACTG 3' forward \\
\hline & 5' GGGCGGGAGAAAGTAGCA 3' reverse \\
\hline \multirow[t]{2}{*}{ MMP-9 } & 5' CCCACTTACTITGGAAACG 3' forward \\
\hline & 5' GAAGATGAATGGAAATACGC 3' reverse \\
\hline \multirow[t]{2}{*}{ TIMP-1 } & 5' GCCTCTGGCATCCTCTTG 3' forward \\
\hline & 5' CTGCGGTTCTGGGACTTG 3' reverse \\
\hline \multirow[t]{2}{*}{ TIMP-2 } & 5' CCAAAGCAGTGAGCGAGAA 3' forward \\
\hline & 5' CCCAG GGCAC AATAA AGTC 3' reverse \\
\hline \multirow[t]{2}{*}{ TGF-beta-1 } & 5' AGAGATTCAAGTCAAACTGTGGAG 3' forward \\
\hline & 5' CCAAGGTAACGCCAGGAA 3' reverse \\
\hline
\end{tabular}

Abbreviation: $G A P D H$, glyceraldehyde-3-phosphate dehydrogenase; $C O L$, collagen; MMP, matrix metalloproteinase; TIMP, tissue inhibitor of metalloproteinase; $T G F$, transforming growth factor.

and MMP-9 were normalized relative to viable cell numbers determined from the MTT assay.

\section{Enzyme-linked immunosorbent assay (ELISA)}

An ELISA was used to measure the concentration of TGF- $\beta 1$ in conditioned medium (culture supernatant) of tendon cells. The medium was aspirated and transferred to the wells of a 96-well ELISA plate that was pre-coated with mouse anti-TGF- $\beta 1$ antibody $(360 \mu \mathrm{g} / \mathrm{ml}, 100 \mu \mathrm{l} /$ well; R\&D Systems, Minneapolis, MN) overnight at room temperature, according to the manufacturer's procedures. The plate was then read using a microplate reader set to measure absorbance at $450 \mathrm{~nm}$ (VICTOR $^{\mathrm{TM}} \mathrm{X} 3$ Multilabel Plate Reader; PerkinElmer Inc, Waltham, MA). Recombinant TGF- $\beta 1$ was serially diluted from 0 to $2000 \mathrm{pg} / \mathrm{ml}$, and the readings were plotted to generate a standard curve. The amount of TGF- $\beta 1$ production was normalized relative to viable cell numbers determined from the MTT assay after subtracted the value of culture medium.

\section{Statistical analysis}

All data from the MTT assay and densitometric analysis were expressed as mean \pm SEM values. The analysis was performed with SPSS 18.0 software for Windows (SPSS Inc., Chicago, IL). Tenocytes among the three age groups were compared using the nonparametric Kruskal-Wallis test. The Mann-Whitney $U$-test was used for comparisons between any two groups. $P$ values less than 0.05 were considered significant.

\section{Results}

Effect of aging on tenocyte viability

Data from MTT assays revealed that aging lowered the relative $\mathrm{OD}_{570 \mathrm{~nm}}$ values of the aliquots (Figure 1). After $24 \mathrm{~h}$, the respective $\mathrm{OD}_{570 \mathrm{~nm}}$ values of the middle-aged and old rats were $60.9 \% \pm 11.4 \%$ and $43.0 \% \pm 1.5 \%$ of those of young rats. After $48 \mathrm{~h}$, the respective $\mathrm{OD}_{570 \mathrm{~nm}}$ values of the middle-aged and old rats were $46.0 \% \pm$ $1.8 \%$ and $39.8 \% \pm 1.8 \%$ of those of young rats. This result indicated that the viable cell numbers of tenocytes might decrease with age.

\section{Effect of aging on mRNA expression}

Quantitative real-time PCR was used to amplify and simultaneously quantify our target mRNAs. Changes in gene expressions were reported as multiples of increases relative to young rats. Quantitative real-time PCR revealed that levels of mRNAs that encode type-I collagen and TGF- $\beta 1$ were essentially indistinguishable in tenocytes from young, middle-aged, and old rats (Figure $2 \mathrm{~A}$ and F). However, $M M P-2$ and -9 mRNA expressions increased significantly with age $(p<0.001$; Figure $2 \mathrm{~B}$ and $\mathrm{C}$ ). Furthermore, as compared with young rats, mRNAs that encode TIMP-1 and -2 were significantly decreased in tenocytes from the old rats $(p<0.001$; Figure 2D and E).

Effect of aging on enzymatic activities of MMP-2 and -9 Gelatin zymography analysis of the activities of MMP-2 and MMP-9 revealed that MMP-2 made a greater

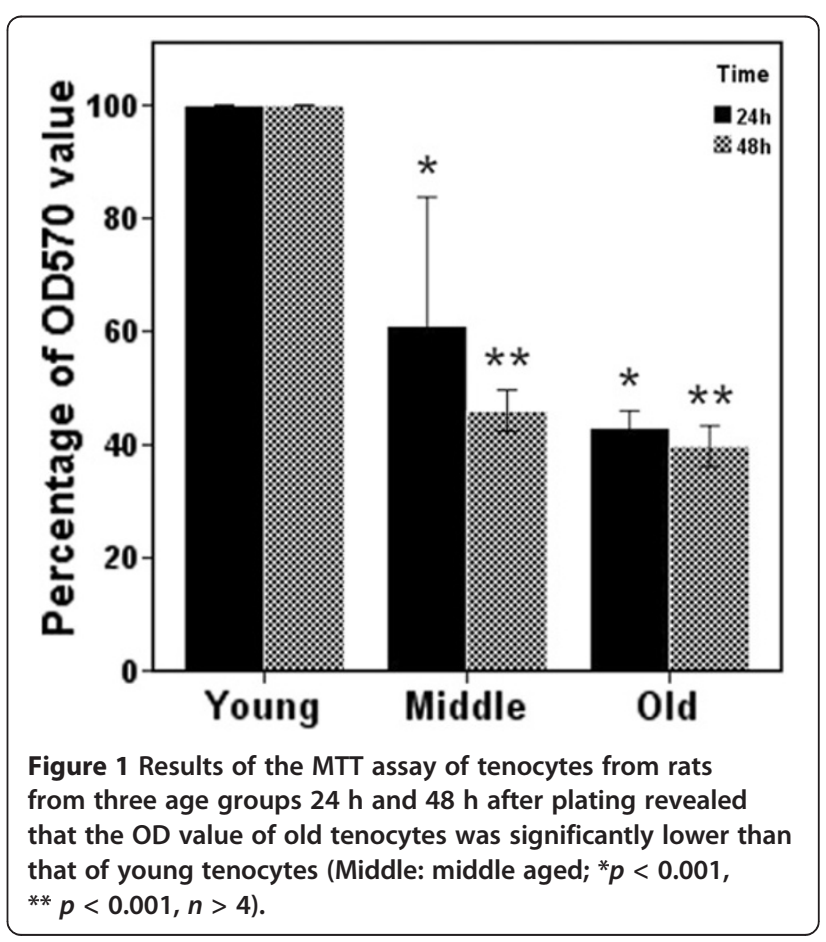




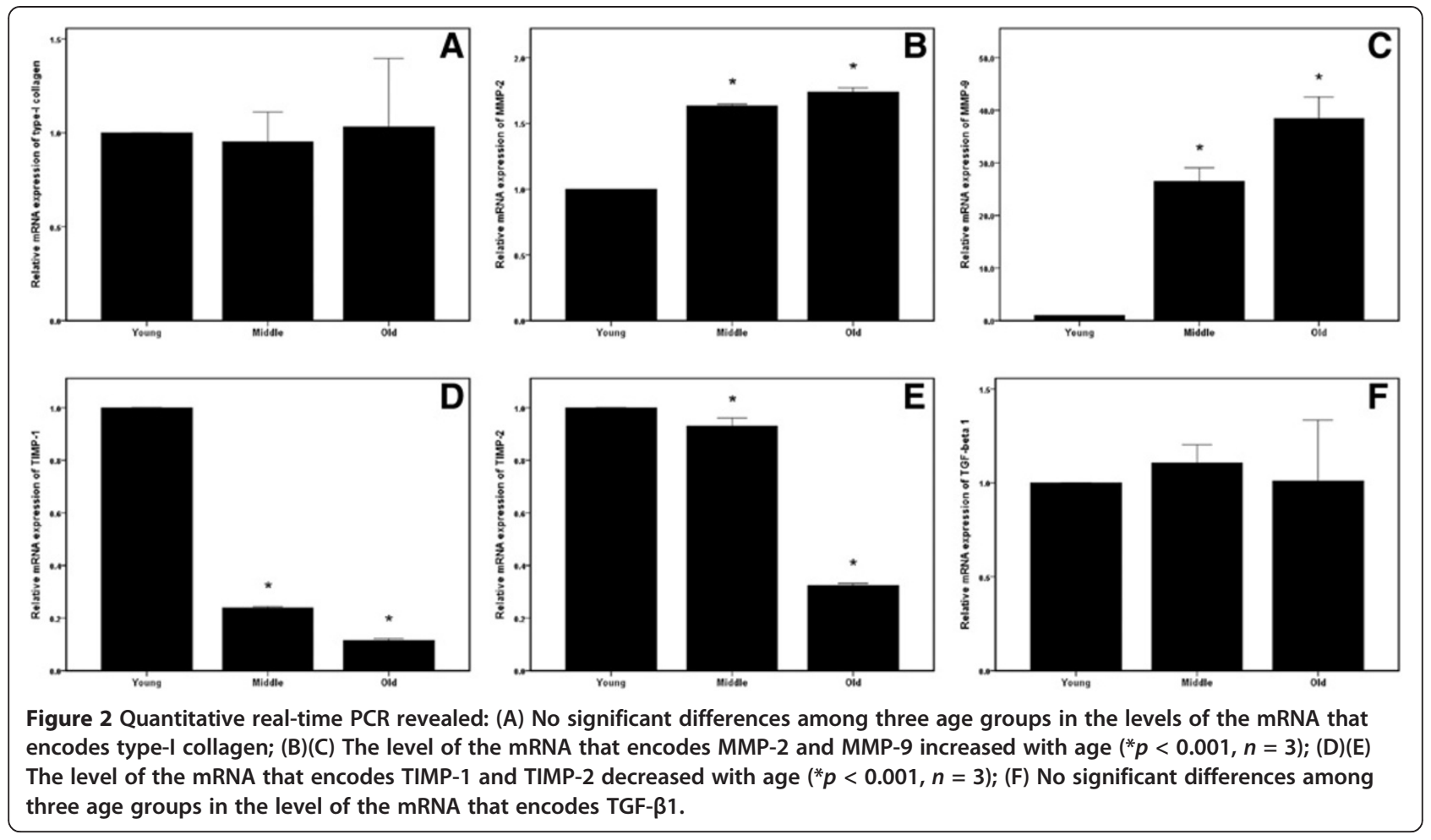

contribution to the total gelatinase activity in tendon cells than MMP-9 did (Figure 3A). The activities of both MMP-2 and MMP-9 were analyzed for the different age groups by subtracting densitometric readings from the background value and normalizing the data by using the number of viable cells determined using the MTT assay. Senescent tenocytes showed significantly higher gelatinase activities than young tenocytes $(p<0.05$; Figure 3B and $\mathrm{C}$ ). This Finding indicates that both MMP-2 and MMP-9 activities increase in an age-dependent manner.

\section{Effect of aging on TGF- $\beta 1$ secretion}

The concentration of TGF- $\beta 1$ in the conditioned medium were $95.9 \mathrm{pg} / \mathrm{ml}, 95.8 \pm 1.51 \mathrm{pg} / \mathrm{ml}, 98.9 \pm$ $2.55 \mathrm{pg} / \mathrm{ml}$, and $97.9 \pm 1.59 \mathrm{pg} / \mathrm{ml}$ for culture medium only and the young, middle-aged, and old tenocytes, respectively. After subtracting the value of culture medium and normalizing the data by using the number of viable cells from MTT assay, the percentage of TGF- $\beta 1$ production was indistinguishable in the conditioned medium from the tenocytes collected from rats of different ages (Figure 4).

\section{Discussion}

Tenocytes-the basic cellular component of tendons-produce collagens, other proteins, and matrix proteoglycans [24]. Healing of injured tendons proceeds via three overlapping stages: inflammation, regeneration, and remodeling $[24,25]$. Each stage prepares the healing process for the following stage, so the impairment of one stage may negatively impact the next one. Tenocyte proliferation is one of the principal steps in the regeneration phase of tendon healing. The results of this study indicate that tenocyte viability (which may compose of cell proliferation ability and metabolism) decreases with aging. This might partially account for the poor healing observed in aging tendons. Similar results have been obtained in studies of wound healing, where the proliferative capacity of fibroblast progressively decreases over time [26,27].

Matrix turnover, which involves both the synthesis and degradation of matrix components, is important for the maintenance and repair of tendons. Type-I collagen constitutes around $60 \%$ of the dry mass of the tissue and approximately $95 \%$ of total collagen [6]. It appears that highly stressed tendons show increased levels of collagen turnover [28]. A study of pathologic human Achilles tendon showed that levels of collagen type-I and -III mRNAs were significantly higher in tendons with chronic pain or spontaneous rupture than in normal tendons [10]. However, the present study demonstrated that aging did not affect the level of the mRNA that encodes type-I collagen. The expression of type-I collagen mRNA is not expected to be a response of aging-related collagen degradation.

The tendon matrix is constantly remodeled throughout life. A relatively high level of matrix remodeling is common in tendons such as the supraspinatus tendon, and this process is linked to degenerative pathology [8]. It appears that MMPs play a key role in regulating 


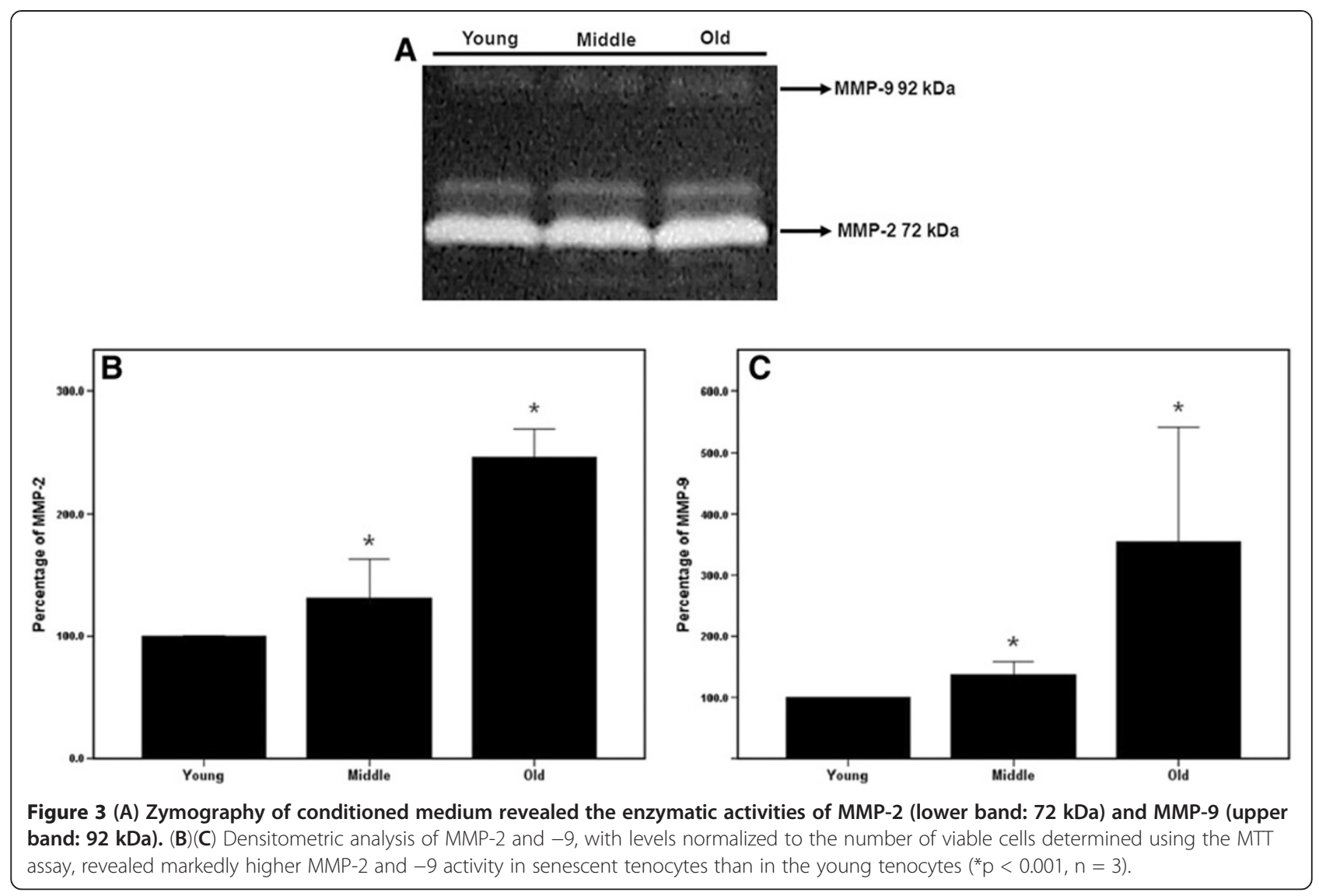

matrix remodeling, as they are considered responsible for the degradation of collagens and proteoglycans $[7,29]$. The results of our present study reveal that the activities of both MMP-2 and MMP-9 are higher in the tendons of aging rats than in the tendons of young rats. To the best of our knowledge, this is the first study to

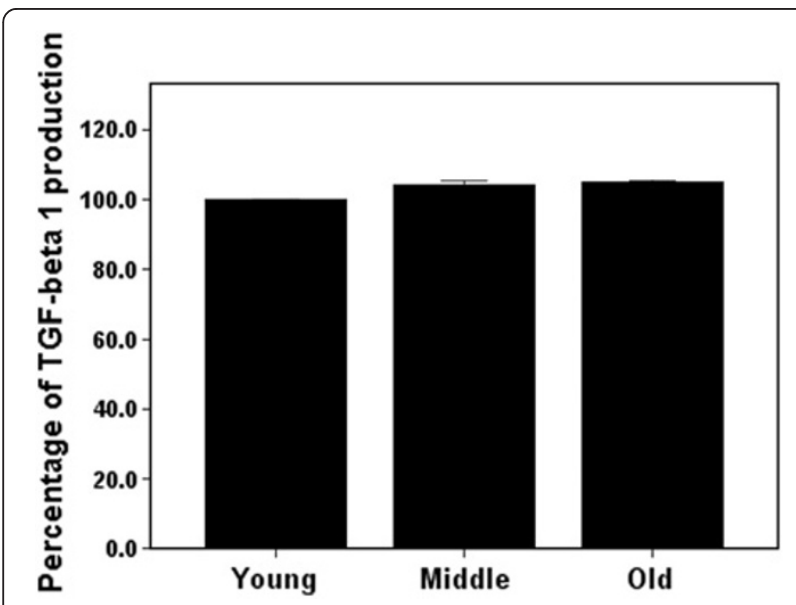

Figure 4 The percentage of TGF- $\beta 1$ production in conditioned medium from cultured tendon cells was not affected by the age of the rats from which they were derived $(n=3)$. measure gelatinase activities in aging tenocytes. However, a similar age-dependent increase in MMP-2 or MMP-9 activity was reported for samples of the skin, heart, articular cartilage, and even plasma [30-33]. It is reasonable to postulate that tendon degeneration may result from the aging-induced over-expression of gelatinase activity. Regarding TIMPs, our data revealed that both TIMP-1 and TIMP-2 mRNA expressions were decreased in old tenocytes, suggesting the activities of MMP-2 and -9 in old tenocytes, under less inhibitory effect from TIMP-1 and -2, may further have a more negative impact on the integrity of tendon matrix. These findings provide a molecular mechanism that accounts for the effect of aging on tendon healing. The overexpression of gelatinase activities may impair the turnover of matrix, which could lead to a qualitatively different and mechanically less stable tendon that is more susceptible to damage.

The transforming growth factor- $\beta$ is active during almost all stages of tendon healing. During inflammation, TGF- $\beta$ has a variety of effects on the regulation of cellular migration and proliferation, as well as on the stimulation of collagen production [15]. During tendon synthesis, TGF- $\beta 1$ significantly promoted the accumulation of COL1A1 mRNA in cultured tendon fibroblasts 
[34]. For tendon remodeling, TGF- $\beta 1$ regulates $M M P-2$ expression at the transcriptional and post-transcriptional levels by inducing an early increase in $M M P-2$ transcription and an increase in the half-life of $M M P-2$ mRNA [21]. It is also thought that TGF- $\beta$ exerts a selective effect on ECM deposition by modulating the action of other growth factors on metalloproteinase and TIMP expression [35]. Increased synthesis of TGF- $\beta 1$ has also been demonstrated for tendon fibroblasts subjected to strain as well as in tendinosis fibroblast cultures [36,37]. However, our study demonstrated that although aging could increase the activities of MMP-2 and -9 , aging is not significantly associated with TGF- $\beta 1$ expression. These observations suggest that TGF- $\beta 1$ does not play a major role in either the aging process related to tendinopathy or the age-related regulation of gelatinase expression.

As for other cell culture models, there are several limitations of the model used in the present study. For instance, the behavior of explanted tendon cells is not identical to the behavior of tendon cells in their natural matrix environment in vivo [38,39]. Therefore, one should always be cautious about translating culture data directly to the in vivo situation. Further animal studies are needed to assess the physiological relevance of our findings. Aging may alter cell activity, but likely also alters the biochemical environment [40]. It may be speculated that using a reduced level of fetal bovine serum (FBS) in culture medium might better simulate the aging condition. Although the design of the present study did not address the effects of different biochemical environment, in previous investigations, it was clearly shown that there was a decreased proliferation rate when lower level of FBS was used. Besides, independent of the levels of FBS in culture medium, there was a better proliferation in cells from young donors than cells from old donors at all times assessed [41]. Meanwhile, immobilization has been demonstrated for an increase of catabolic process of extracellular matrix by increasing the expression of MMPs [42,43]. It is possible that differences in physical activity between the age groups might partly account for the findings in this study. Further study may be performed to compare the MMPs expression between the effects of inactivity and aging.

\section{Conclusion}

This study demonstrated an age-related increase in the level of gelatinase (MMP-2 and MMP-9) activities and decrease in the mRNA expression of TIMP-1 and TIMP-2 in tenocytes, without any effect of age on the levels of mRNA that encodes type-I collagen or TGF- $\beta 1$ activity. These results imply that aging might exert a negative effect on tendon structure or its healing process by a mechanism that involves increased MMP-2 and MMP-9 activities, and decreased proliferation of tenocytes. Furthermore, the common growth regulator TGF- $\beta$ does not appear to affect the aging process in tendons.

\section{Competing interests \\ The authors declare that they have no competing interests.}

\section{Authors' contributions}

TY: main investigator, drafting and revision of the manuscript. JHS: main investigator, data interpretation and revision of the manuscript. KPS: data interpretation and proofreading. MCL: statistical analysis. $\mathrm{CH}$ : data interpretation. WC: chief supervisor, study design and revision of the manuscript. All authors read and approved the final manuscript.

\section{Acknowledgements}

This research was supported financially by the National Science Council of R. O.C. (Taiwan).

\section{Author details}

${ }^{1}$ Departement of Physical Medicine and Rehabilitation, Chang Gung Memorial Hospital, Linkou, Taiwan. ${ }^{2}$ Graduate Institute of Clinical Medical Sciences, Chang Gung University, Kwei-Shan Tao-Yuan, Taiwan. ${ }^{3}$ College of Medicine, Change Gung University, Kwei-Shan Tao-Yuan, Taiwan.

Received: 21 May 2012 Accepted: 23 December 2012

Published: 2 January 2013

\section{References}

1. Chard MD, Cawston TE, Riley GP, Gresham GA, Hazleman BL: Rotator cuff degeneration and lateral epicondylitis: a comparative histological study. Ann Rheum Dis 1994, 53:30-34.

2. Astrom M, Rausing A: Chronic Achilles tendinopathy. A survey of surgical and histopathologic findings. Clin Orthop Relat Res 1995, 316:151-164.

3. Dressler MR, Butler DL, Wenstrup R, Awad HA, Smith F, Boivin GP: A potential mechanism for age-related declines in patellar tendon biomechanics. J Orthop Res 2002, 20:1315-1322.

4. Kannus P, Jozsa L: Histopathological changes preceding spontaneous rupture of a tendon. A controlled study of 891 patients. J Bone Joint Surg Am 1991, 73:1507-1525.

5. Jones GC, Corps AN, Pennington CJ, Clark IM, Edwards DR, Bradley MM, Hazleman BL, Riley GP: Expression profiling of metalloproteinases and tissue inhibitors of metalloproteinases in normal and degenerate human achilles tendon. Arthritis Rheum 2006, 54:832-842.

6. Riley $\mathrm{G}$ : The pathogenesis of tendinopathy. A molecular perspective. Rheumatology (Oxford) 2004, 43:131-142.

7. Riley G: Tendinopathy-from basic science to treatment. Nat Clin Pract Rheumatol 2008, 4:82-89.

8. Riley GP, Curry V, DeGroot J, van El B, Verzijl N, Hazleman BL, Bank RA: Matrix metalloproteinase activities and their relationship with collagen remodelling in tendon pathology. Matrix Biol 2002, 21:185-195.

9. Visse $\mathrm{R}$, Nagase $\mathrm{H}$ : Matrix metalloproteinases and tissue inhibitors of metalloproteinases: structure, function, and biochemistry. Circ Res 2003, 92:827-839.

10. Ireland D, Harrall R, Curry V, Holloway G, Hackney R, Hazleman B, Riley G: Multiple changes in gene expression in chronic human Achilles tendinopathy. Matrix Biol 2001, 20:159-169.

11. Salo T, Turpeenniemi-Hujanen T, Tryggvason K: Tumor-promoting phorbol esters and cell proliferation stimulate secretion of basement membrane (type IV) collagen-degrading metalloproteinase by human fibroblasts. J Biol Chem 1985, 260:8526-8531.

12. Aimes RT, Quigley JP: Matrix metalloproteinase-2 is an interstitial collagenase. Inhibitor-free enzyme catalyzes the cleavage of collagen fibrils and soluble native type I collagen generating the specific 3/4- and 1/4-length fragments. J Biol Chem 1995, 270:5872-5876.

13. Dudhia J, Scott CM, Draper ER, Heinegard D, Pitsillides AA, Smith RK: Aging enhances a mechanically-induced reduction in tendon strength by an active process involving matrix metalloproteinase activity. Aging Cell 2007, 6:547-556.

14. Kingsley DM: The TGF-beta superfamily: new members, new receptors, and new genetic tests of function in different organisms. Genes Dev 1994, 8:133-146. 
15. Molloy $T$, Wang $Y$, Murrell $G$ : The roles of growth factors in tendon and ligament healing. Sports Med 2003, 33:381-394.

16. Sporn MB, Roberts AB, Shull JH, Smith JM, Ward JM, Sodek J: Polypeptide transforming growth factors isolated from bovine sources and used for wound healing in vivo. Science 1983, 219:1329-1331.

17. Wrana JL, Sodek J, Ber RL, Bellows CG: The effects of platelet-derived transforming growth factor beta on normal human diploid gingival fibroblasts. Eur J Biochem 1986, 159:69-76.

18. Kerr LD, Miller DB, Matrisian LM: TGF-beta 1 inhibition of transin/ stromelysin gene expression is mediated through a Fos binding sequence. Cell 1990, 61:267-278.

19. Kerr LD, Olashaw NE, Matrisian LM: Transforming growth factor beta 1 and CAMP inhibit transcription of epidermal growth factor- and oncogeneinduced transin RNA. J Biol Chem 1988, 263:16999-17005.

20. Overall $\mathrm{CM}$, Wrana JL, Sodek J: Independent regulation of collagenase, 72$\mathrm{kDa}$ progelatinase, and metalloendoproteinase inhibitor expression in human fibroblasts by transforming growth factor-beta. J Biol Chem 1989, 264:1860-1869.

21. Overall CM, Wrana JL, Sodek J: Transforming growth factor-beta regulation of collagenase, $72 \mathrm{kDa}$-progelatinase, TIMP and PAI-1 expression in rat bone cell populations and human fibroblasts. Connect Tissue Res 1989, 20:289-294.

22. Deie M, Marui T, Allen CR, Hildebrand KA, Georgescu HI, Niyibizi C, Woo SL: The effects of age on rabbit MCL fibroblast matrix synthesis in response to TGF-beta 1 or EGF. Mech Ageing Dev 1997, 97:121-130.

23. Tsai WC, Pang JH, Hsu CC, Chu NK, Lin MS, Hu CF: Ultrasound stimulation of types I and III collagen expression of tendon cell and upregulation of transforming growth factor beta. J Orthop Res 2006, 24:1310-1316.

24. Leadbetter WB: Cell-matrix response in tendon injury. Clin Sports Med 1992, 11:533-578.

25. Broughton $\mathrm{G} 2 \mathrm{nd}$, Janis JE, Attinger CE: Wound healing: an overview. Plast Reconstr Surg 2006, 117:1e-S-32e-S.

26. Van de Kerkhof PC, Van Bergen B, Spruijt K, Kuiper JP: Age-related changes in wound healing. Clin Exp Dermatol 1994, 19:369-374.

27. Bruce SA, Deamond SF: Longitudinal study of in vivo wound repair and in vitro cellular senescence of dermal fibroblasts. Exp Gerontol 1991, 26:17-27.

28. Riley GP, Harrall RL, Constant CR, Chard MD, Cawston TE, Hazleman BL: Tendon degeneration and chronic shoulder pain: changes in the collagen composition of the human rotator cuff tendons in rotator cuff tendinitis. Ann Rheum Dis 1994, 53:359-366.

29. Sharma P, Maffulli N: Biology of tendon injury: healing, modeling and remodeling. J Musculoskelet Neuronal Interact 2006, 6:181-190.

30. Lindsey ML, Goshorn DK, Squires CE, Escobar GP, Hendrick JW, Mingoia JT, Sweterlitsch SE, Spinale FG: Age-dependent changes in myocardial matrix metalloproteinase/tissue inhibitor of metalloproteinase profiles and fibroblast function. Cardiovasc Res 2005, 66:410-419.

31. Mine $S$, Fortunel NO, Pageon $H$, Asselineau D: Aging alters functionally human dermal papillary fibroblasts but not reticular fibroblasts: a new view of skin morphogenesis and aging. PLoS One 2008, 3:e4066.

32. Gepstein A, Shapiro S, Arbel G, Lahat N, Livne E: Expression of matrix metalloproteinases in articular cartilage of temporomandibular and knee joints of mice during growth, maturation, and aging. Arthritis Rheum 2002, 46:3240-3250.

33. Bonnema DD, Webb CS, Pennington WR, Stroud RE, Leonardi AE, Clark LL, McClure CD, Finklea L, Spinale FG, Zile MR: Effects of age on plasma matrix metalloproteinases (MMPs) and tissue inhibitor of metalloproteinases (TIMPs). J Card Fail 2007, 13:530-540.

34. Chan KM, Fu SC, Wong YP, Hui WC, Cheuk YC, Wong MW: Expression of transforming growth factor beta isoforms and their roles in tendon healing. Wound Repair Regen 2008, 16:399-407.

35. Edwards DR, Murphy G, Reynolds JJ, Whitham SE, Docherty AJ, Angel P, Heath JK: Transforming growth factor beta modulates the expression of collagenase and metalloproteinase inhibitor. EMBO J 1987, 6:1899-1904.

36. Robbins JR, Evanko SP, Vogel KG: Mechanical loading and TGF-beta regulate proteoglycan synthesis in tendon. Arch Biochem Biophys 1997, 342:203-211.

37. Fu SC, Wang W, Pau HM, Wong YP, Chan KM, Rolf CG: Increased expression of transforming growth factor-beta1 in patellar tendinosis. Clin Orthop Relat Res 2002, 400:174-183.
38. Fu SC, Cheuk YC, Chan KM, Hung LK, Wong MW: Is cultured tendon fibroblast a good model to study tendon healing? J Orthop Res 2008, 26:374-383.

39. Leigh DR, Abreu EL, Derwin KA: Changes in gene expression of individual matrix metalloproteinases differ in response to mechanical unloading of tendon fascicles in explant culture. J Orthop Res 2008, 26:1306-1312.

40. Sprenger CC, Plymate SR, Reed MJ: Aging-related alterations in the extracellular matrix modulate the microenvironment and influence tumor progression. Int J Cancer 2010, 127:2739-2748.

41. Pradel W, Mai R, Gedrange T, Lauer G: Cell passage and composition of culture medium effects proliferation and differentiation of human osteoblast-like cells from facial bone. J Physiol Pharmacol 2008, 59(Suppl 5):47-58.

42. Sun YL, Thoreson AR, Cha SS, Zhao C, An KN, Amadio PC: Temporal response of canine flexor tendon to limb suspension. J Appl Physiol 2010, 109:1762-1768.

43. Kjaer M: Role of extracellular matrix in adaptation of tendon and skeletal muscle to mechanical loading. Physiol Rev 2004, 84:649-698.

doi:10.1186/1471-2474-14-2

Cite this article as: Yu et al:: Aging is associated with increased activities of matrix metalloproteinase-2 and -9 in tenocytes. BMC Musculoskeletal Disorders 2013 14:2

\section{Submit your next manuscript to BioMed Central and take full advantage of:}

- Convenient online submission

- Thorough peer review

- No space constraints or color figure charges

- Immediate publication on acceptance

- Inclusion in PubMed, CAS, Scopus and Google Scholar

- Research which is freely available for redistribution

Submit your manuscript at www.biomedcentral.com/submit
C Biomed Central 